basic practical guide indispensable to anyone attempting an experiment with a pulsed-neutron spectrometer; in fact the numerous general remarks about experimental technique and spectrometer design are equally useful for the reactor-based scientist and the book should be compulsory reading matter for any new graduate student in the field. It is refreshing to find a discussion of the health hazards associated with working in weak irradiating fields; one wonders why a subject of such enormous potential importance has escaped attention in previous treatises on neutron scattering.

Apart from trivial typographical errors, I can fault the book only on two minor scores. In my view the first chapter does not do justice to its title of "Beyond Thermal Neutrons". I was expecting to be told of new science to be studied but read only the standard liturgy on the usefulness of neutron scattering. The chapter is really a thumbnail sketch of classical problems in neutron scattering and should have been titled as such. My second, less serious, objection concerns the partial use of SI units (for lengths only apparently). This is insufficient to satisfy the pedant but is more than enough to be irksome to those schooled in the conventional usage.

Roger Pynn is a solid-state physicist at the Institut Laue-Langevin, Grenoble, and a consultant for the Los Alamos National Laboratory pulsed neutron project.

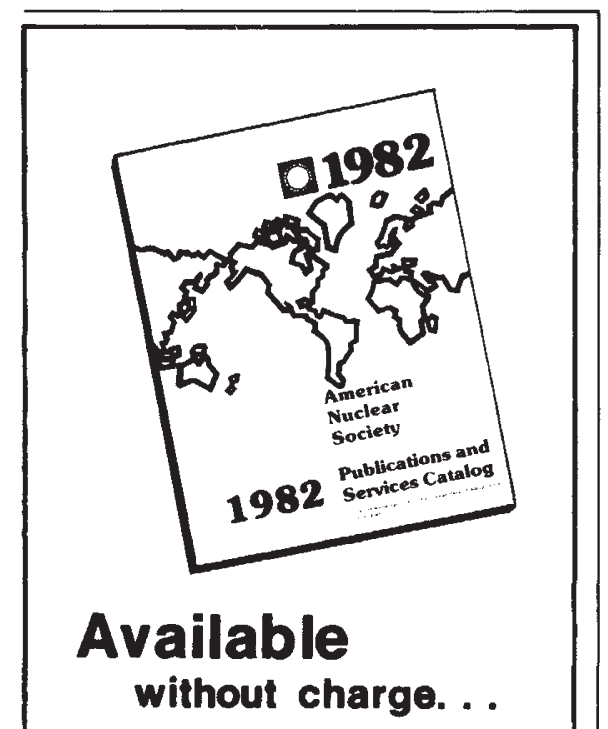

The ANS publications catalog is available without cost or obligation. Write today for your free copy.

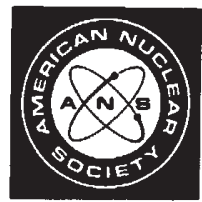

\section{AMERICAN NUCLEAR SOCIETY}

555 North Kensington Avenue La Grange Park, Illinois 60525 USA

Circle No.43 on Reader Enquiry Card.

\title{
Relating to halogenated hydrocarbons
}

\section{Alastair Hay}

Halogenated Biphenyls, Terphenyls, Naphthalenes, Dibenzodioxins and Related Products. Topics in Environmental Health, Vol. 4. Edited by R.D. Kimbrough. Pp.406. ISBN 0-444-80253-3. (Elsevier/North-Holland Biomedical: 1981.) \$95, Dfl. 195.

TEN years ago the only environmental pollutant people were familiar with was DDT. Today you could list dozens of additional names. Two types of chemicals which would be included are the polychlorinated biphenyls (PCBs) and the polychlorinated dibenzodioxins (PCDDs).

Both the PCBs and the PCDDs, known collectively as chlorinated hydrocarbons, have been widely discussed, but the halogenated isomers of these compounds are not as well known. This new book on halogenated hydrocarbons will remedy this situation. Here, for the first time in a single volume, the properties of the PCBs and PCDDs are considered in relation to the whole family of halogenated hydrocarbons.

In the case of the PCBs there is some irony in the fact that the very physical properties which made these chemicals so popular are the reasons why they are so much of a problem today. The attributes of the PCBs were said to include thermal stability and resistance to both oxidation and chemical degradation. An estimated 1 million tons have been produced since 1930.

Numerous surveys have shown that the residues of PCBs can be detected in human beings. The problem appears to have been caused by eating food - and fish in particular - contaminated with PCBs, simply because there is such an abundance of these chemicals in the environment. Once these facts were known the bottom dropped out of the PCB market. Government regulations - long overdue - helped to hasten their demise. But it was only production which was affected; we still have the mess to clean up.

It is a different problem with the PCDDs, which are produced as unwanted by-products in the course of making chlorinated phenols. Often they remain as contaminants in the finished phenolic product, some of which are widely used. Pentachlorophenol, for example, is a common wood preservative. And 2,4,5-trichlorophenol - contaminated with the highly toxic $2,3,7,8$-tetrachlorodibenzo- $p$-dioxin (TCDD) - is the starting point for the manufacture of the herbicide 2,4,5-T.

Although the threat from environmental exposure to both PCBs and PCDDs is still unknown, there is much more evidence about the hazard to workers occupationally exposed to them. It emerges that, as far as toxicity is concerned, there are many similarities between the two substances.

In her introduction to this book, Renate Kimbrough says that it was thought to be desirable to discuss PCBs, PCDDs and related compounds in one book to help convey "a better understanding of their action and the complexities of their toxic effects".

The book does just that and it does it very well. Kimbrough has persuaded leading scientists in the field to discuss the chemicals in depth and to draw comparisons between them wherever possible.

The subjects included cover everything from the chemistry of these chemicals to their production, usage, and animal and human toxicology. In addition, there are valuable case studies of human populations exposed to PCBs in Japan and to TCDD at Seveso in Italy. The last chapter, by the editor herself, discusses the problems and health effects of occupational exposure to such substances.

The book is likely to become one of the standard texts for both students and researchers concerned about the health effects of exposure to PCBs, dioxins and their ilk. It is a joy to read a book as well edited as this, where there is no overlap between chapters and where all the contributors have stuck to their brief. The reader is left in no doubt that the toxicity of these halogenated aromatic compounds is indeed complex, but that there are many similarities between such chemicals in the way they exert their toxic effects.

Alastair Hay is a Lecturer in the Department of Chemical Pathology at the University of Leeds.

\section{Foram stratigraphy}

\section{F.T. Banner}

Stratigraphical Atlas of Fossil Foraminifera. Edited by D.G. Jenkins and J.W. Murray. Pp.310. UK ISBN 0-85312-210-5; US ISBN 0-470-27191-4. (Ellis Horwood/Halsted: 1981.) £25, $\$ 79.95$.

IN ONE concise yet comprehensive handbook, the value of fossil foraminifera to the stratigraphical geology of the British Isles is demonstrated at last. Before this publication, the information was scattered and no clear over-view could readily be obtained. Now, a collaboration by 23 authors (drawn from the petroleum industry, industrial consultancies, universities and the Institute of Geological Sciences) has provided a summary of all useful, published information, and careful 
basic practical guide indispensable to anyone attempting an experiment with a pulsed-neutron spectrometer; in fact the numerous general remarks about experimental technique and spectrometer design are equally useful for the reactor-based scientist and the book should be compulsory reading matter for any new graduate student in the field. It is refreshing to find a discussion of the health hazards associated with working in weak irradiating fields; one wonders why a subject of such enormous potential importance has escaped attention in previous treatises on neutron scattering.

Apart from trivial typographical errors, I can fault the book only on two minor scores. In my view the first chapter does not do justice to its title of "Beyond Thermal Neutrons". I was expecting to be told of new science to be studied but read only the standard liturgy on the usefulness of neutron scattering. The chapter is really a thumbnail sketch of classical problems in neutron scattering and should have been titled as such. My second, less serious, objection concerns the partial use of SI units (for lengths only apparently). This is insufficient to satisfy the pedant but is more than enough to be irksome to those schooled in the conventional usage.

Roger Pynn is a solid-state physicist at the Institut Laue-Langevin, Grenoble, and a consultant for the Los Alamos National Laboratory pulsed neutron project.

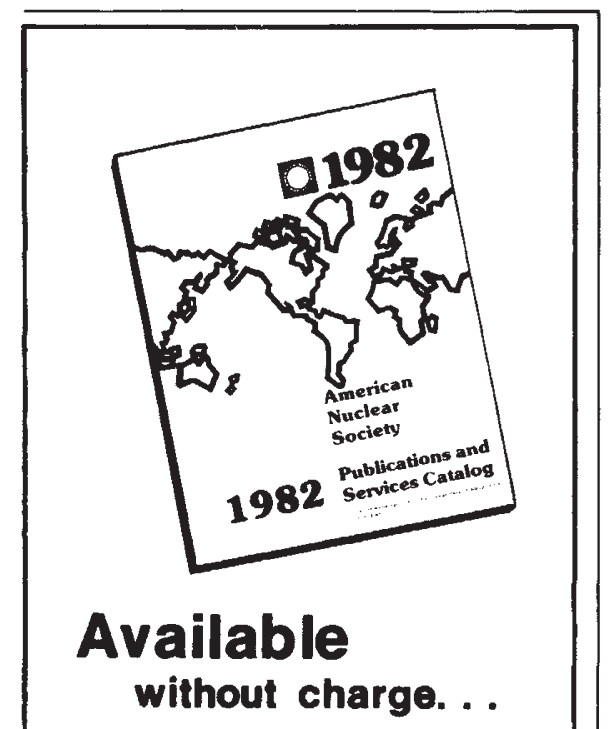

The ANS publications catalog is available without cost or obligation. Write today for your free copy.

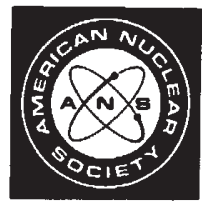

\section{AMERICAN NUCLEAR SOCIETY}

555 North Kensington Avenue La Grange Park, Illinois 60525 USA

Circle No.43 on Reader Enquiry Card.

\section{Relating to halogenated hydrocarbons}

\section{Alastair Hay}

Halogenated Biphenyls, Terphenyls, Naphthalenes, Dibenzodioxins and Related Products. Topics in Environmental Health, Vol. 4. Edited by R.D. Kimbrough. Pp.406. ISBN 0-444-80253-3. (Elsevier/North-Holland Biomedical: 1981.) \$95, Dfl. 195.

TEN years ago the only environmental pollutant people were familiar with was DDT. Today you could list dozens of additional names. Two types of chemicals which would be included are the polychlorinated biphenyls (PCBs) and the polychlorinated dibenzodioxins (PCDDs).

Both the PCBs and the PCDDs, known collectively as chlorinated hydrocarbons, have been widely discussed, but the halogenated isomers of these compounds are not as well known. This new book on halogenated hydrocarbons will remedy this situation. Here, for the first time in a single volume, the properties of the PCBs and PCDDs are considered in relation to the whole family of halogenated hydrocarbons.

In the case of the PCBs there is some irony in the fact that the very physical properties which made these chemicals so popular are the reasons why they are so much of a problem today. The attributes of the PCBs were said to include thermal stability and resistance to both oxidation and chemical degradation. An estimated 1 million tons have been produced since 1930.

Numerous surveys have shown that the residues of PCBs can be detected in human beings. The problem appears to have been caused by eating food - and fish in particular - contaminated with PCBs, simply because there is such an abundance of these chemicals in the environment. Once these facts were known the bottom dropped out of the PCB market. Government regulations - long overdue - helped to hasten their demise. But it was only production which was affected; we still have the mess to clean up.

It is a different problem with the PCDDs, which are produced as unwanted by-products in the course of making chlorinated phenols. Often they remain as contaminants in the finished phenolic product, some of which are widely used. Pentachlorophenol, for example, is a common wood preservative. And 2,4,5-trichlorophenol - contaminated with the highly toxic $2,3,7,8$-tetrachlorodibenzo- $p$-dioxin (TCDD) - is the starting point for the manufacture of the herbicide 2,4,5-T.

Although the threat from environmental exposure to both PCBs and PCDDs is still unknown, there is much more evidence about the hazard to workers occupationally exposed to them. It emerges that, as far as toxicity is concerned, there are many similarities between the two substances.

In her introduction to this book, Renate Kimbrough says that it was thought to be desirable to discuss PCBs, PCDDs and related compounds in one book to help convey "a better understanding of their action and the complexities of their toxic effects".

The book does just that and it does it very well. Kimbrough has persuaded leading scientists in the field to discuss the chemicals in depth and to draw comparisons between them wherever possible.

The subjects included cover everything from the chemistry of these chemicals to their production, usage, and animal and human toxicology. In addition, there are valuable case studies of human populations exposed to PCBs in Japan and to TCDD at Seveso in Italy. The last chapter, by the editor herself, discusses the problems and health effects of occupational exposure to such substances.

The book is likely to become one of the standard texts for both students and researchers concerned about the health effects of exposure to PCBs, dioxins and their ilk. It is a joy to read a book as well edited as this, where there is no overlap between chapters and where all the contributors have stuck to their brief. The reader is left in no doubt that the toxicity of these halogenated aromatic compounds is indeed complex, but that there are many similarities between such chemicals in the way they exert their toxic effects.

Alastair Hay is a Lecturer in the Department of Chemical Pathology at the University of Leeds.

\section{Foram stratigraphy}

\section{F.T. Banner}

Stratigraphical Atlas of Fossil Foraminifera. Edited by D.G. Jenkins and J.W. Murray. Pp.310. UK ISBN 0-85312-210-5; US ISBN 0-470-27191-4. (Ellis Horwood/Halsted: 1981.) £25, $\$ 79.95$.

IN ONE concise yet comprehensive handbook, the value of fossil foraminifera to the stratigraphical geology of the British Isles is demonstrated at last. Before this publication, the information was scattered and no clear over-view could readily be obtained. Now, a collaboration by 23 authors (drawn from the petroleum industry, industrial consultancies, universities and the Institute of Geological Sciences) has provided a summary of all useful, published information, and careful 